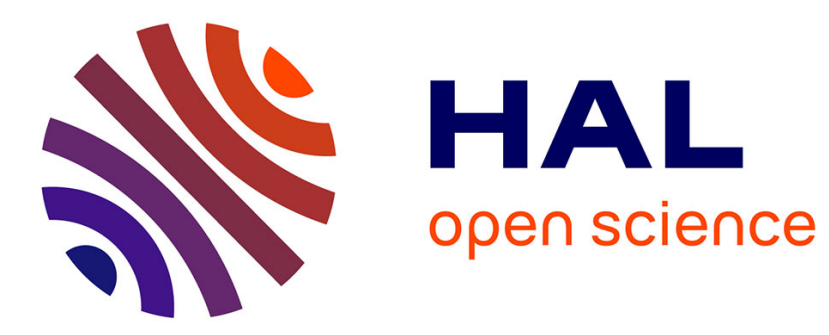

\title{
Patterned ferrimagnetic thin films of spinel ferrites obtained directly by laser irradiation
}

Isabel Pasquet, Lionel Presmanes, Corine Bonningue, Philippe Tailhades

\section{To cite this version:}

Isabel Pasquet, Lionel Presmanes, Corine Bonningue, Philippe Tailhades. Patterned ferrimagnetic thin films of spinel ferrites obtained directly by laser irradiation. Applied Surface Science, 2013, vol. 283, pp. 283-289. 10.1016/j.apsusc.2013.05.160 . hal-00863291

\section{HAL Id: hal-00863291 \\ https://hal.science/hal-00863291}

Submitted on 18 Sep 2013

HAL is a multi-disciplinary open access archive for the deposit and dissemination of scientific research documents, whether they are published or not. The documents may come from teaching and research institutions in France or abroad, or from public or private research centers.
L'archive ouverte pluridisciplinaire HAL, est destinée au dépôt et à la diffusion de documents scientifiques de niveau recherche, publiés ou non, émanant des établissements d'enseignement et de recherche français ou étrangers, des laboratoires publics ou privés. 


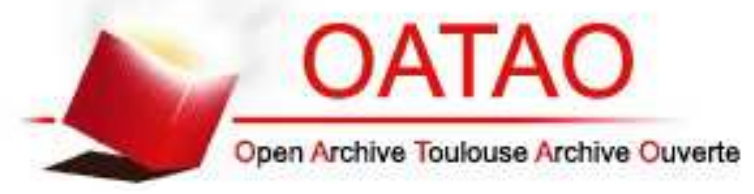

\section{Open Archive TOULOUSE Archive Ouverte (OATAO)}

OATAO is an open access repository that collects the work of Toulouse researchers and makes it freely available over the web where possible.

This is an author-deposited version published in : http://oatao.univ-toulouse.fr/ Eprints ID : 9429

To link to this article : doi:10.1016/j.apsusc.2013.05.160

URL : http://dx.doi.org/10.1016/j.apsusc.2013.05.160

To cite this version : Pasquet, Isabel and Presmanes, Lionel and

Bonningue, Corine and Tailhades, Philippe Patterned ferrimagnetic thin films of spinel ferrites obtained directly by laser irradiation. (2013)

Applied Surface Science, vol. 283 . pp. 283-289. ISSN 0169-4332

Any correspondance concerning this service should be sent to the repository administrator: staff-oatao@ listes-diff.inp-toulouse.fr 


\title{
Patterned ferrimagnetic thin films of spinel ferrites obtained directly by laser irradiation
}

\author{
I. Pasquet ${ }^{a, b}$, L. Presmanes ${ }^{a, b}$, C. Bonningue ${ }^{a, b}$, Ph. Tailhades ${ }^{a, b, *}$ \\ a Université de Toulouse, UPS, INPT, Institut Carnot CIRIMAT, 118, route de Narbonne, F-31062 Toulouse Cedex 9, France \\ ${ }^{\mathrm{b}}$ CNRS, Institut Carnot Cirimat, F-31062 Toulouse, France
}

Keywords:

Some spinel ferrites can be oxidized or transformed at moderate temperatures. Such modifications were carried out on thin films of mixed cobalt copper ferrites and maghemite, by heating small regions with a low-power laser spot applied for about $100 \mathrm{~ns}$. The very simple laser heating process, which can be done directly with a conventional photolithographic machine, made it possible to generate two-dimensional magnetization heterogeneities in ferrimagnetic films. Such periodic structures could display the specific

Laser patterning

Laser irradiation

Spinel ferrite

Iron oxide

Magnonic crystals

Magneto-photonic crystals

\section{Introduction}

From the pioneering works of Yablonovitchh [1] and John [2] optical periodic structures, called photonic crystals, have attracted much attention, not only because of their fundamental interest, but also because of their potential technological applications due to their original collective properties [3]. Making such periodic structures with ferro or ferrimagnetic materials, is also very attractive for several reasons. Firstly, optical indices can be tailored by an external magnetic field in such structures, due to the magnetic birefringence and dichroic properties of the core material. Tunable optical devices, which can be called "magneto-photonic crystals", can thus be imagined [4,5]. The second reason is that two-dimensional magnetization heterogeneities in a ferro or ferrimagnetic material, can lead to a structure able to manage spin wave propagation. These magnetic counterparts of photonic crystals are generally called "magnonic crystals"[6-8]. The two-dimensional magnetization heterogeneities can be holes or a second material, having different magnetic properties than the matrix inside which

\footnotetext{
* Corresponding author at: Université de Toulouse, UPS, INPT, Institut Carnot CIRIMAT, 118, route de Narbonne, F-31062 Toulouse Cedex 9, France. Tel.: +3305615561 74; fax: +330561556163.

E-mail address: tailhade@chimie.ups-tlse.fr (Ph. Tailhades).
}

it is inserted. Such magnonic devices could find technological applications in narrow-band optical or microwave filters or high speed switches [9].

2D periodic structuration of magnetic films, has already been performed to make magnonic crystals. However, the materials used were single garnet films or magnetic alloys and the method carried out resorted to quite heavy optical or electron lithography processing [9-12]. This paper proposes a very simple laser processing of spinel ferrite films, with the aim to fabricate new magnetic devices, for instance magneto-photonic or magnonic crystals. Laser beams or spots have already been used to anneal [13-16], sinter [17] or pattern [18-24] a lot of oxides, notably spinel oxides $[25,26]$. Of course, spinel ferrites were chosen for this work, because of their ferrimagnetic properties, which can be easily adjusted by proper cationic substitutions. But the other reason, which is the key to successful patterning with low-power laser spots, is that spinel ferrite thin films can often display a real "thermal reactivity" at moderate temperatures. "Thermal reactivity" means reactivity towards oxygen for spinel containing cations capable of higher valence states [27], or metastability for strongly non-stoichiometric ferrites $[28,29]$ or quite low sintering temperatures, mainly for copper substituted ferrites [30,31]. Such thermal sensitivities are already used for optical data storage [32-34].

This paper will mainly focus on thin films of mixed cobalt copper ferrites, because of their high sensitivity to laser irradiation. It will also give another example with laser patterned $\gamma-\mathrm{Fe}_{2} \mathrm{O}_{3}$ thin films. 


\section{Experimental}

\subsection{Sample preparation}

Thin films of spinel ferrites were prepared by radio-frequency sputtering of $10 \mathrm{~cm}$ diameter oxide targets. For mixed cobalt copper ferrites, an oxide target having $\mathrm{Co}: \mathrm{Cu}: \mathrm{Fe}$ cations in the proportions 0.15:0.85:2 was used. The second target was made of magnetite $\mathrm{Fe}_{3} \mathrm{O}_{4}$. The sputtering machine was an Alcatel A450 equipped with a radio-frequency-generator $(13.56 \mathrm{MHz})$ device as well as a pumping system (a mechanical pump coupled with a turbo molecular pump) which reaches residual pressures down to $10^{-5} \mathrm{~Pa}$, a gas flow controller, a water cooled target holder and two water cooled sample holders. The films were deposited on glass substrates with an average arithmetic roughness lower than $0.5 \mathrm{~nm}$.

Conventionally, a residual vacuum of $5 \times 10^{-5}$ Pa was reached in the sputtering chamber before introducing the argon deposition gas. In order to obtain various microstructures for $\mathrm{Co}_{0.15} \mathrm{Cu}_{0.85} \mathrm{Fe}_{2} \mathrm{O}_{4}$, target-substrate distances of 5 and $8 \mathrm{~cm}$ and argon pressures of 0.5 and $2 \mathrm{~Pa}$, were used. Moreover, for each experimental condition, the targets were sputtered for $20 \mathrm{~min}$ before starting film deposition on the glass substrate. The sputtering power was maintained at about $3 \mathrm{~W} \mathrm{~cm}^{-2}$ for each of the sputtering conditions used.

Below, the mixed cobalt copper ferrite samples are named "Pxdy" with $\mathbf{x}$ the value of argon pressure in Pascal, and $\mathbf{y}$ the sample target distance in centimetres.

Magnetite films were obtained by magnetite target sputtering $\mathrm{P} 0.5 \mathrm{~d} 5$ conditions. These samples were oxidized at $300^{\circ} \mathrm{C}$ for $2 \mathrm{~h}$ in order to form $\gamma-\mathrm{Fe}_{2} \mathrm{O}_{3}$ metastable phase.

\subsection{Laser patterning}

Most of the patterning experiments were done using a DWL 200 machine from Heidelberg Instruments MikroTechnik. This machine is generally dedicated to mask manufacture for optical lithography. It is a high precision tool using pixel generation technology by He-Cd laser scanning ( $\lambda=442 \mathrm{~nm}$, maximal power $125 \mathrm{~mW}$ ). The writing speed was about $1 \mathrm{~mm}^{2} / \mathrm{s}$ or $10 \mathrm{M}$ pixels/s. The average duration of laser insolation for each pixel, is close to $100 \mathrm{~ns}$ and the maximal light energy is $7.8 \mathrm{~J} / \mathrm{cm}^{2}$. The optical system is made of an Autofocus, which has a pneumatic servo-control to correct the flatness defects. The tuning range of the Autofocus is $70 \mu \mathrm{m}$ and its $z$ resolution is $100 \mathrm{~nm}$. The working distance between the sample and the objective lens was $100 \mu \mathrm{m}$.

Other experiments were carried out with a machine designed for the production of masters for optical disc manufacturing. The $476 \mathrm{~nm}$ wavelength of an Ar laser was focused by an objective lens with a numerical aperture of 0.8 , flying over the sample at a distance close to $1 \mathrm{~mm}$. The writing time for each pixel was close to $100 \mathrm{~ns}$ and the maximal light power at the sample surface was about $20 \mathrm{~mW}$.

\subsection{Characterization techniques}

\subsubsection{X-ray diffraction}

Structural characterizations of films were performed by grazing angle X-ray diffraction $\left(\alpha=1^{\circ}\right)$ on a Siemens D 5000 diffractometer equipped with a Brucker sol-X detector. The X-ray wavelength was that of the copper $K \alpha$ ray $\left(K \alpha_{1}=0.15405 \mathrm{~nm}\right.$ and $\mathrm{K} \alpha_{2}=0.15443 \mathrm{~nm}$ ).

\subsubsection{Raman spectroscopy}

Raman spectra were collected under ambient conditions using a Horiba Scientific Raman microscope fitted with a laser wavelength of $532 \mathrm{~nm}$ and a $100 \times$ objective lens. During the measurement, the resulting laser power at the surface of the sample was adjusted to $1.1 \mathrm{~mW}$. The final spectrum is the average of three $300 \mathrm{~s}$ accumulations. Examination of multiple spots showed that the samples were homogeneous.

\subsubsection{Magnetic measurement}

The magnetic properties were measured in the plane of the films, with a SQUID magnetometer MPMSXL 7 from Quantum design. The maximal applied field for the measurements was $70 \mathrm{k}$ Oe. The magnetizations of the samples were corrected for substrate contribution.

\subsubsection{Thickness measurement and microscopy}

Film thicknesses were measured using a Dektak 3030ST profilometer. Atomic force microscopy (AFM) was carried out with a Veeco Dimension 3000 atomic force microscope, equipped with a super sharp TESP-SS AppNano® tip (nominal resonance frequency $320 \mathrm{kHz}$, nominal radius of curvature $2 \mathrm{~nm}$ ). Magnetic Force Microscopy (MFM) observations were also performed with the same apparatus using magnetized tips ( $\mathrm{Co} / \mathrm{Cr}$ coating, nominal resonance frequency $70 \mathrm{kHz}$ ). AFM was used to reveal the heated areas of the films, where changes in volume occurred due to stress relaxation, oxidation or crystallization. MFM is not really appropriated to study such strong topographic deformations in ferrimagnetic films. Indeed, the magnetic contrast is generally low and the topographic signal due to a high bump or a deep hollow, is difficult to remove totally from the magnetic signal. However, MFM is very powerful to reveal changes in local magnetic properties when there is no topographical modification. MFM was then used only to reveal local maghemite-hematite transformations, which can occur without topographical change and which involve the formation of antiferromagnetic zones in ferrimagnetic ferrite films.

The microstructure of the samples was also investigated by scanning electron microscopy with a JEOL JSM 6700F apparatus. The proportion of cations was determined by EDX (Princeton Gamma Tech). Some patterns were also observed with a Keyence VHX-600 digital optical microscope using a VH-Z100R or VH-Z500R objective system, having both a high resolution and a large depth of field.

\section{Results and discussion}

\subsection{Mixed cobalt copper spinel ferrites}

The ferrite thin films prepared were poorly crystallized but they displayed the main X-ray diffraction (Fig. 1) and Raman peaks (Fig. 2) of the spinel structure. Moreover they were ferromagnetic at room temperature as revealed by their $\mathrm{M}=f(\mathrm{H})$ hysteresis curves (Fig. 3). EDX analyses also showed that the metal chemical composition was $0.15 \mathrm{Co}: 0.85 \mathrm{Cu}: 2 \mathrm{Fe}$, the same as that of the target. The thin films were then made of a $\mathrm{Co}_{0.15} \mathrm{Cu}_{0.85} \mathrm{Fe}_{2} \mathrm{O}_{4}$ spinel ferrite. The samples prepared at $0.5 \mathrm{~Pa}$ argon pressure and $5 \mathrm{~cm}$ from the target (samples P0.5d5), had X-ray diffraction peaks shifted towards the small angles compared to the peak positions for a powder having the same composition. An in-plane compressive stress, making the reticular distances larger in a direction close to the perpendicular of the film surface, was assumed to be responsible for this shift. By contrast, the P2d8 samples were submitted to a slight tensile stress (Fig. 1 and Table 1). Atomic force microscopy clearly shows the polycrystalline structure of the films (Fig. 4), which were made of small crystallites of about $25 \mathrm{~nm}$ and $40 \mathrm{~nm}$ for $100 \mathrm{~nm}$ and $1 \mu \mathrm{m}$ thick samples respectively. The samples prepared at a high argon pressure (P2d8) displayed crystallites aggregated in larger grains separated by porosity. This porosity clearly appeared for P2d8, mainly for $1 \mu \mathrm{m}$ thick films (Fig. 4). 


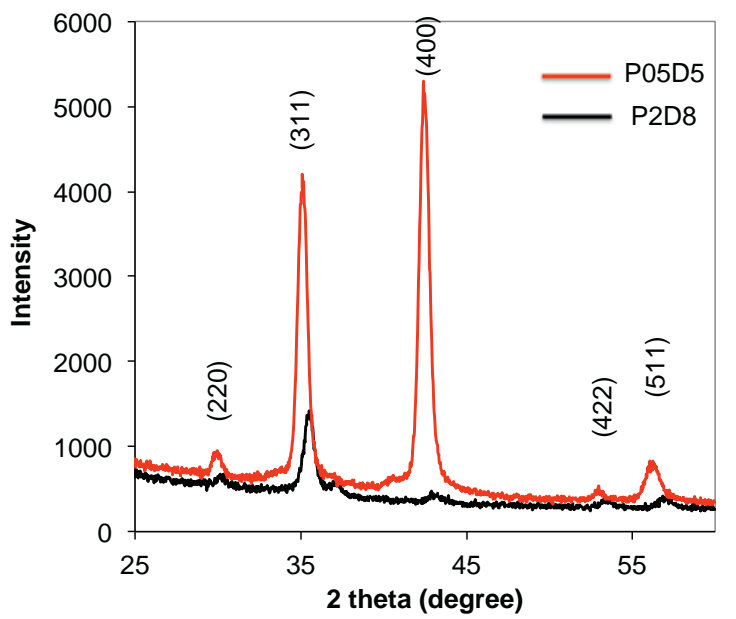

Fig. 1. X-ray diffraction patterns of as-deposited CuCo thin films ( $1 \mu \mathrm{m}$ thick) for two experimental conditions: argon pressure $2 \mathrm{~Pa}$ and target-substrate distance $8 \mathrm{~cm}$ (P2d8); argon pressure 0.5 Pa and target-substrate distance $5 \mathrm{~cm}$ (P05d5).
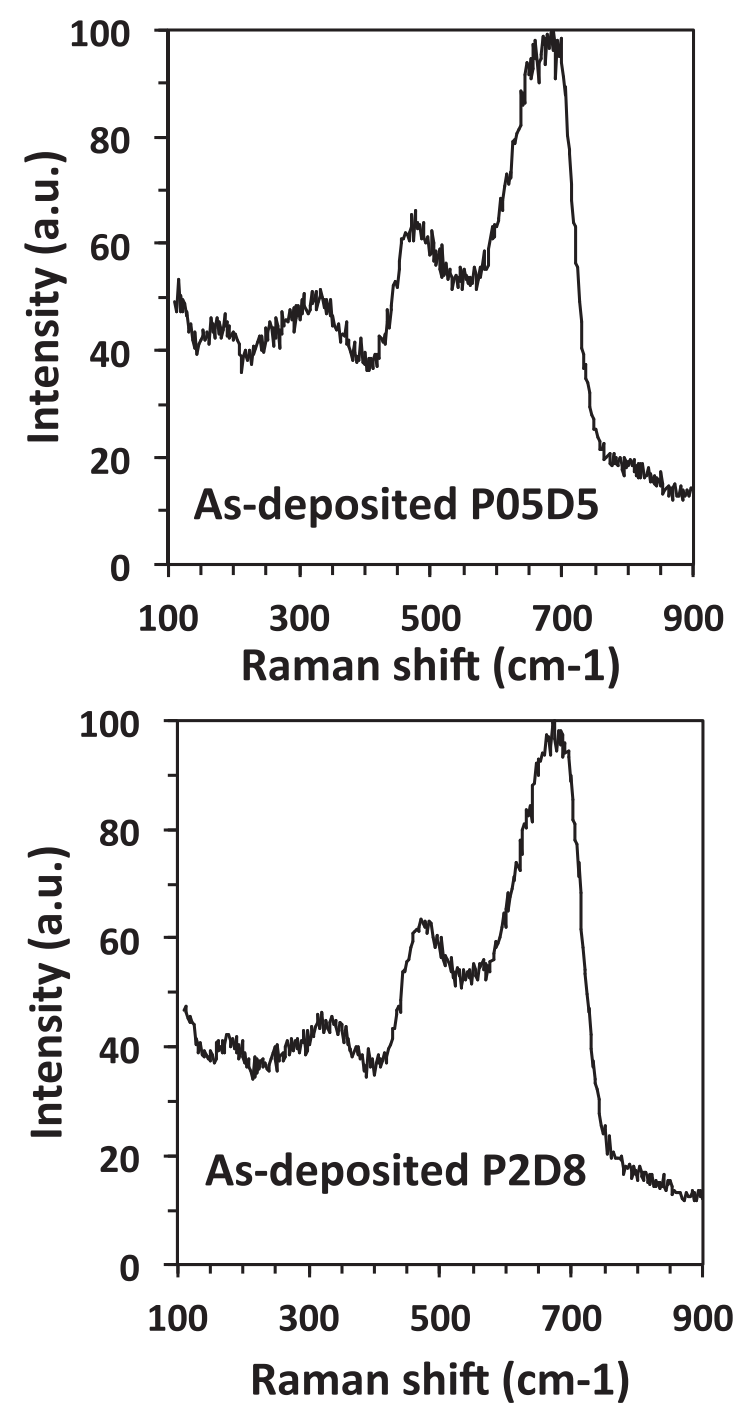

Fig. 2. Raman spectra of as-deposited CuCo thin films (thickness: $1 \mu \mathrm{m}$ ) for experimental conditions P2d8 and P05d5.
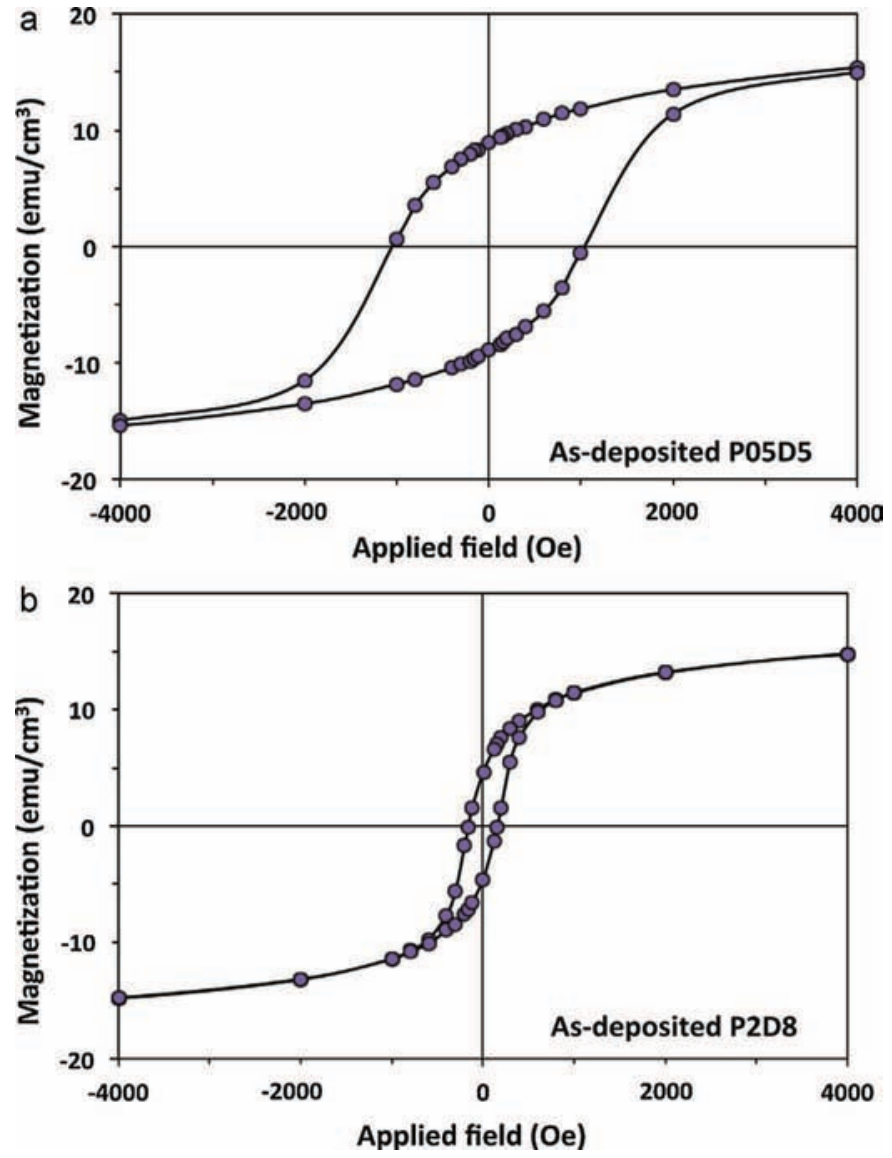

Fig. 3. $M=f(H)$ hysteresis curve at room temperature for $1 \mu \mathrm{m}$ thick samples of mixed cobalt copper ferrite films, prepared in different conditions: (a) argon pressure: $2 \mathrm{~Pa}$, target-substrate distance: $8 \mathrm{~cm}$, (b) argon pressure: $0.5 \mathrm{~Pa}$, targetsubstrate distance: $5 \mathrm{~cm}$.

Preliminary experiments of laser irradiation were carried out on as-deposited films, having a thickness of $70 \mathrm{~nm}$. The laser spot of the mastering machine $(\lambda=476 \mathrm{~nm}$ ) was used for these experiments. Two different behaviours were observed. For the films prepared at low argon pressure, the laser irradiation created bumps, whereas crater-like shaped holes appeared for films obtained at high pressure (Fig. 5). The patterns written were very regular in size and shape for all samples. Their size, however, increased a little bit with the laser power due to the Gaussian profile of the energy of the spot. For instance, the bumps displayed an overall diameter close to $0.3 \mu \mathrm{m}$ and a height of $10 \mathrm{~nm}$ for $5 \mathrm{~mW}$, but these values became $0.6 \mu \mathrm{m}$ and $30 \mathrm{~nm}$, for a power of $15 \mathrm{~mW}$.

Some experiments were carried out to try to understand the phenomena related to pattern formation. At first, thin films were heated at $450{ }^{\circ} \mathrm{C}$ in air (AA samples) or in pure nitrogen (NA samples). It was observed that for AA ferrite layers, it was not possible to get a pattern with a moderate laser power $(5-15 \mathrm{~mW})$. For NA samples, films can be written on, using a slightly higher laser power than for as-deposited ferrites. Pattern formation could then be related to an oxidation phenomenon induced by laser heating.

Table 1

Modifications of the out-of-plane reticular distances due to internal stress in ferrite films.

\begin{tabular}{ll}
\hline Sample & (311) Reticular distance (nm) \\
\hline $\mathrm{Co}_{0.15} \mathrm{Cu}_{0.85} \mathrm{Fe}_{2} \mathrm{O}_{4}$ powder & 0.25274 \\
$\mathrm{P} 0.5 \mathrm{~d} 5$ thin film & 0.25539 \\
$\mathrm{P} 2 \mathrm{~d} 8$ thin film & 0.25267 \\
\hline
\end{tabular}


(a) P2d8

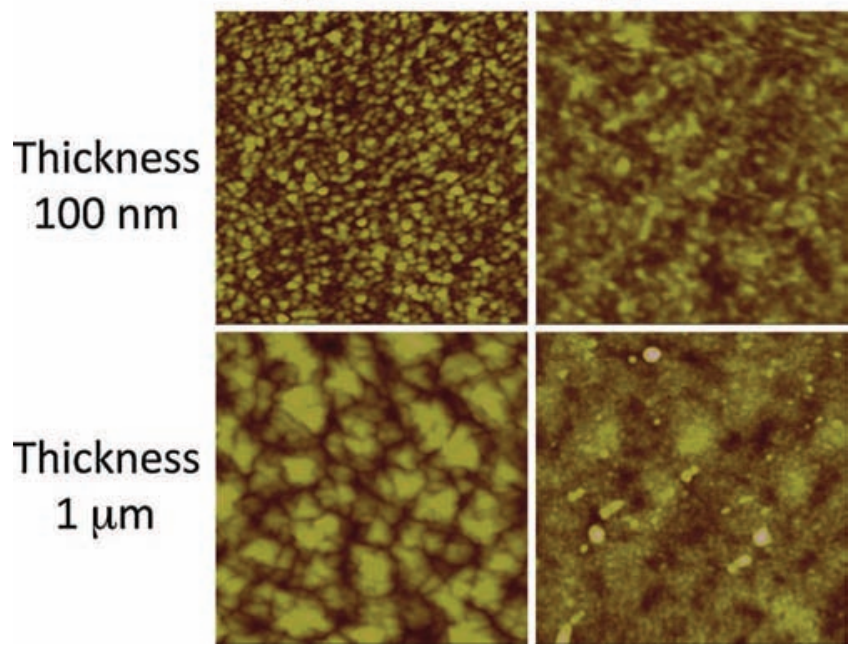

Fig.4. AFM image $(1 \times 1$ micrometers $)$ of the surface of $100 \mathrm{~nm}$ and $1 \mu \mathrm{m}$ thick films, prepared in different conditions: (a) argon pressure: 2 Pa, target-substrate distance: $8 \mathrm{~cm}$, (b) argon pressure: $0.5 \mathrm{~Pa}$, target-substrate distance: $5 \mathrm{~cm}$.

Some spinel oxides, mainly ferrites containing copper, have a low excess of cations (i.e. metallic cations/oxygen anions $>3 / 4$ ). They can be described by a general formula such as: $\mathrm{M}_{x} \mathrm{Fe}_{3-x} \mathrm{O}_{4-\delta}$ $(\delta>0$, M: metallic cations). For such ferrites, non-stoichiometry occurs due to excess of low valence state cations, which are located in oxygen interstices, normally free of cations in the spinel structure. "Interstitial" cuprous ions were already revealed in copper [35,36] or mixed cobalt copper ferrites [37]. The films studied probably display such non-stoichiometry, making cuprous cations the only oxidizable ions, due to the high stability of the other $\mathrm{Cu}^{2+}, \mathrm{Co}^{2+}$ and $\mathrm{Fe}^{3+}$ cationic species. The oxidation could then be written:

$\mathrm{Co}_{0,15} \mathrm{Cu}_{0,85} \mathrm{Fe}_{2} \mathrm{O}_{4-\delta}+\delta / 2 \mathrm{O}_{2} \rightarrow \mathrm{Co}_{0.15} \mathrm{Cu}_{0,85} \mathrm{Fe}_{2} \mathrm{O}_{4}$

Reaction (1), which is induced by the heating effect of the laser irradiation, can occur more or less readily according to the film crystallite size. For as-deposited films, reactivity towards oxygen was high because of low valence state copper ions and small crystallite size. Patterns could then be formed at low laser power. When annealed at $450^{\circ} \mathrm{C}$ in inert gas, cuprous ions remained but their oxidation was more difficult because of larger crystallite size, i.e. because of the lower area of material in contact with the air. Patterns formation required higher laser power. Of course, sample

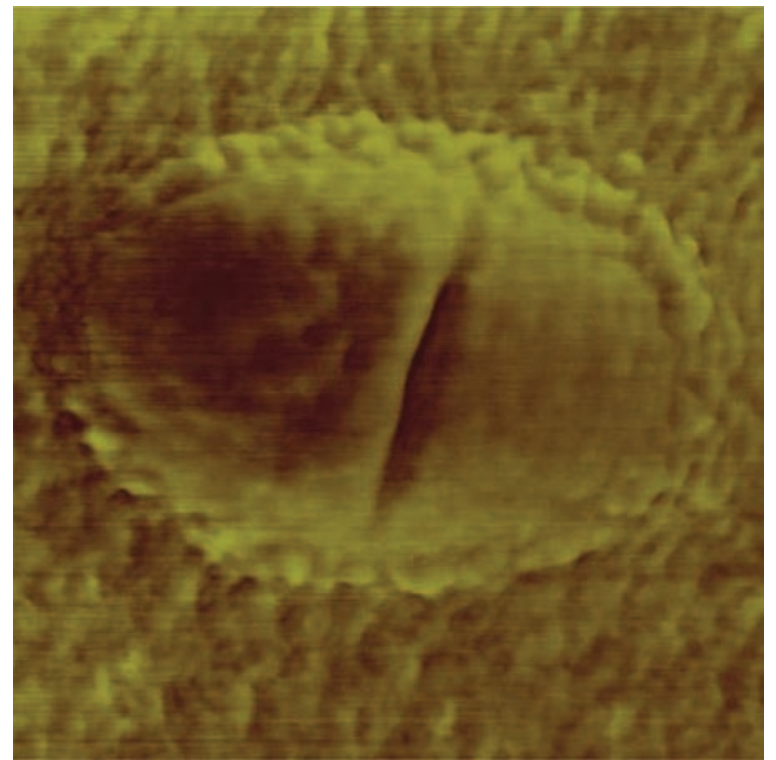

Fig. 6. AFM image (phase mode) showing the increase in crystallite size in the laser heated zones (cobalt copper ferrite film, thickness $70 \mathrm{~nm}, \mathrm{P} 0.5 \mathrm{~d} 5$ ). Image size $600 \mathrm{~nm} \times 600 \mathrm{~nm}$.

annealing in air at $450^{\circ} \mathrm{C}$, was responsible for cuprous ions oxidation, making it impossible to write patterns with moderate laser power.

Although oxidation seems to play a fundamental role in the formation of the patterns, it cannot explain why ferrite films react to the laser irradiation, to give either bumps or holes. Maybe, however, the heat brought by the laser, added to a small heating effect due to the exothermic oxidation, brings enough energy to modify the local microstructure leading to the growth and the sintering of the crystallites. This effect can be especially pronounced for copper ferrites, which can be sintered at quite low temperatures [30,31]. The change in crystallite size was revealed by AFM imaging, for the bumps formed in P0.5d5 samples (Fig. 6). The microstructural change goes also with topographical modification due to the mechanical stress developed during the growth of the films. For films P0.5d5 submitted to a compressive stress in their plane, the microstructural change goes with the formation of a bump. By contrast, tensile stress leads to "holes" with crater-like shapes in P2d8 layers. (a)

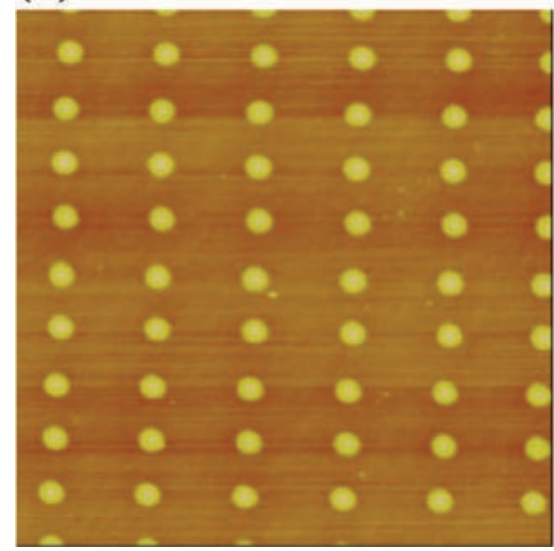

(b)

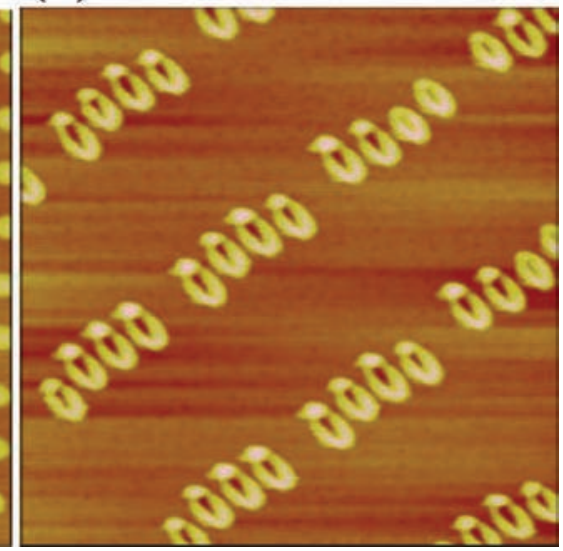

Fig. 5. Patterning of films prepared in different conditions: (a) argon pressure: $0.5 \mathrm{~Pa}$, target-substrate distance: $5 \mathrm{~cm}$ (AFM Image $10 \mu \mathrm{m} \times 10 \mu \mathrm{m}$ ); (b) argon pressure: 2 Pa, target-substrate distance: $8 \mathrm{~cm}$ (AFM Image $7 \mu \mathrm{m} \times 7 \mu \mathrm{m})$ 
P05d5

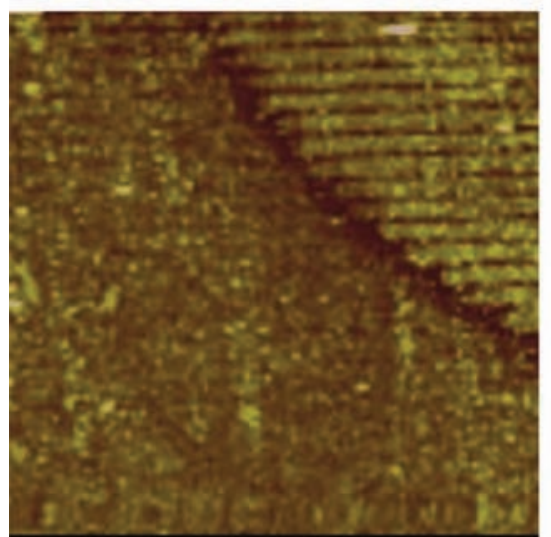

$\mathrm{P} 2 \mathrm{~d} 8$

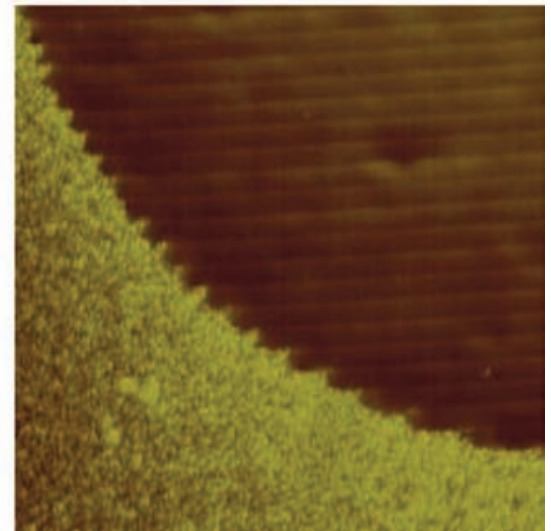

Fig. 7. AFM images showing the raised (bright) and hollow (dark) zones for P0.5d5 (a) and P2d8, respectively. The thickness of the films is $1 \mu \mathrm{m}$. The image size is $10 \mu \mathrm{m} \times 10 \mu \mathrm{m}$.

(a)

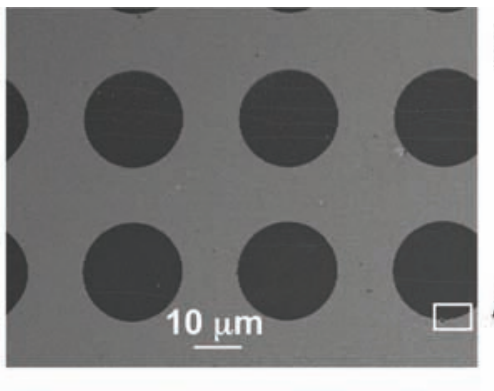

(c)

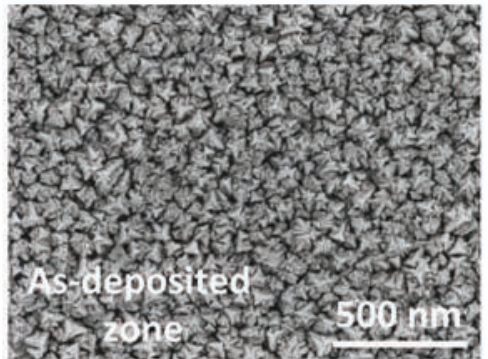

(b)

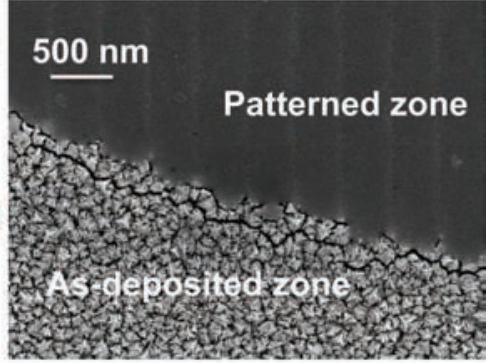

(d)

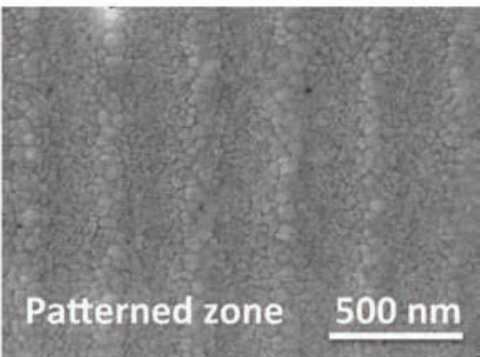

Fig. 8. (a) SEM image of laser patterned P2d8 film (thickness: $1 \mu \mathrm{m}$ ); (b-d) details of as-deposited and patterned zones.

Very similar results were obtained for thicker samples irradiated by the $442 \mathrm{~nm}$ laser spot of the conventional photolithography machine. For $1 \mu \mathrm{m}$ thick samples, hollow zones can be observed for P2d8 films and raised zones for P0.5d5 films (Fig. 7). As previously shown, the laser spot involves crystallite growth and sintering. In the P2d8 hollow zones, the crystallites were a little bit larger than those in the as-deposited regions (Fig. 8). Moreover, the roughness was decreased and the porosity deleted in these laser treated zones. In the P0.5d5 raised zones, the crystallite sizes were also increased. Unlike the P2d8 samples, which were submitted to different internal stresses, laser heating did lead however to an increase in roughness. The roughness was mainly due to grooves resulting from the scan of the laser spot, as clearly revealed by AFM images (Fig. 7a).

Spinel ferrites with periodic patterns engraved inside, can then be obtained by direct laser processing. Because of the versatility of this process, periodic structures very similar to those used for magnonic crystals made of garnets [9], can be directly patterned in P2d8 spinel ferrites. It will be interesting to study the potential magneto-photonic or magnonic effects of such structured ferrimagnetic spinel oxides in the near future.

It is also important to show that with the conventional photolithography machine used, it is possible to write very small

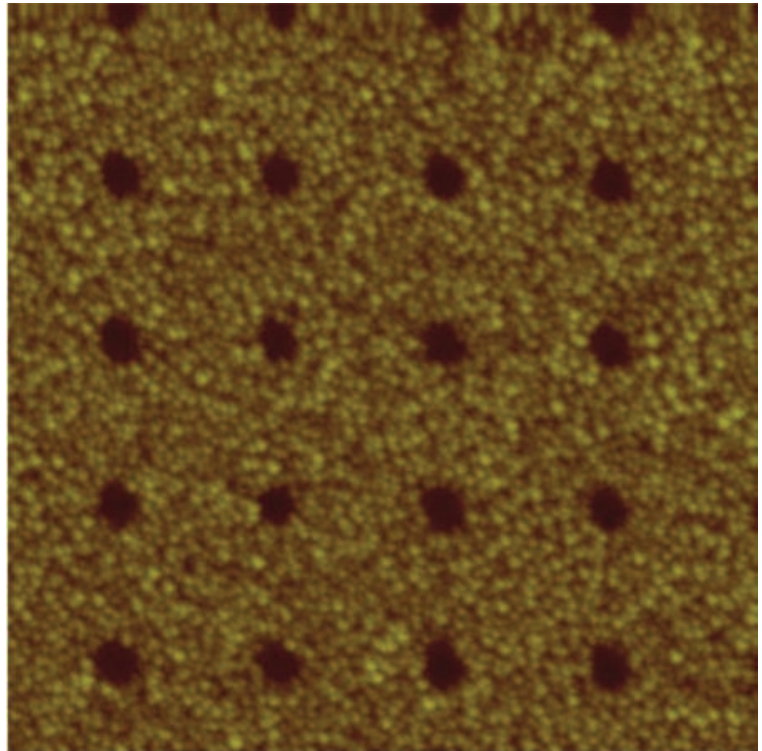

Fig. 9. Submicronic patterns in P2d8 film (thickness of the film: $1 \mu \mathrm{m}$ ) $(10 \mu \mathrm{m} \times 10 \mu \mathrm{m}$ AFM image). 


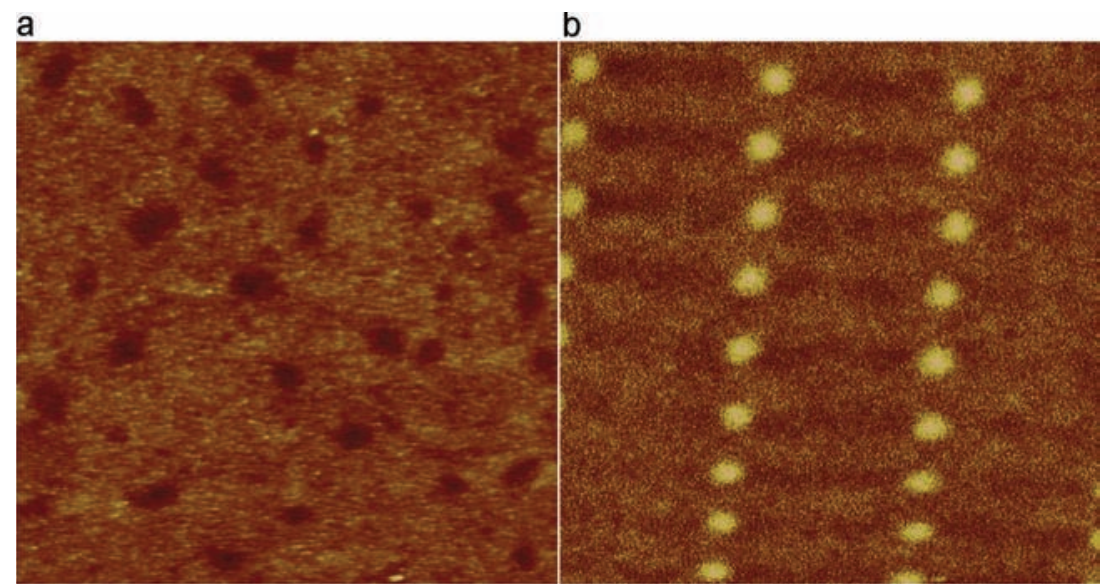

Fig. 10. AFM image (a) and the corresponding MFM image (b) of a $\gamma-\mathrm{Fe}_{2} \mathrm{O}_{3}$ film locally transformed into $\alpha$-Fe $\mathrm{O}_{3}$ by laser heating (size of the images: $8 \mu \mathrm{m} \times 8 \mu \mathrm{m}$ ).

patterns in films of cobalt copper spinel ferrites. For instance, submicronic patterns were obtained in P2d8 films (Fig. 9). That makes the preparation of miniaturized structures possible.

\subsection{Maghemite films}

The maghemite $\left(\gamma-\mathrm{Fe}_{2} \mathrm{O}_{3}\right)$ is a metastable spinel phase obtained by oxidation of magnetite $\left(\mathrm{Fe}_{3} \mathrm{O}_{4}\right)$. It can be transformed into the thermodynamically stable $\alpha-\mathrm{Fe}_{2} \mathrm{O}_{3}$, which has the corundum structure. This transformation, which occurs at a moderate temperature (\#300-600 ${ }^{\circ} \mathrm{C}$ ) varying mainly with crystallite size and mechanical stress [29], can be achieved not only for fine powders but also for thin films of maghemite.

Some writing experiments were done with the $476 \mathrm{~nm}$ laser spot on $25 \mathrm{~nm}$ thick maghemite films obtained by oxidation at $300^{\circ} \mathrm{C}$ of magnetite samples. For laser power in between 7.5 and $10 \mathrm{~mW}$, no topographical modifications were revealed. Careful MFM observations showed, however, magnetic contrasts reproducing the patterns programmed on the laser machine (Fig. 10). The magnetic contrasts came from the local transformations of the ferrimagnetic $\gamma-\mathrm{Fe}_{2} \mathrm{O}_{3}$ film, which interacted with the magnetized tip of the microscope, into antiferromagnetic $\alpha-\mathrm{Fe}_{2} \mathrm{O}_{3}$ zones, for which the magnetic interactions with the tip were lower.

The metastability of some spinel ferrite thin films, thus offers another possibility to create periodic structures by a very simple and direct laser irradiation process. The periodic "magnetic heterogeneities" created inside the ferromagnetic film could, also generate the specific properties of a magneto-photonic or magnonic crystal.

\section{Conclusion}

Thin films of mixed cobalt copper spinel ferrites and maghemite displayed thermal reactivity, which makes their patterning possible by a low-power laser spot. By controlling the elaboration parameters or the ferrite composition, holes, bumps or local phase changes can be created inside spinel ferrite films, by this very simple laser-based process. Ferrimagnetic films with two-dimensional periodic heterogeneities of magnetization, can then be prepared. Such films meet the basic requirements of magnonic or magneto-photonic crystals. Moreover, due to the huge possibilities of composition and non-stoichiometry, offered by the spinel ferrite family, patterned periodic structures could be made using a simple process, with ferrites having the relevant properties to make effective magneto-photonic or magnonic crystals.

\section{Acknowledgements}

This work was supported by the RENATECH technological platform from Institut Carnot LAAS-CNRS, member of the RTB network. The authors particularly thank Dr. Pierre François Calmon.

\section{References}

[1] E. Yablonovitch, Inhibited spontaneous emission in solid-state physics and electronics, Physical Review Letters 58 (1987) 2059-2062.

[2] S. John, Strong localization of photons in certain disordered dielectric superlattices, Physical Review Letters 58 (1987) 2486-2489.

[3] J.D. Joannopoulos, R.D. Meade, J.N. Winn, Photonic Crystals: Molding the Flow of Light, Princeton University Press, Princeton, 1995.

[4] S.A. Nikitov, Ph. Tailhades, Optical modes conversion in magneto-photonic crystal waveguides, Optics Communications 199 (2001) 389-397.

[5] I.L. Lyubchanskii, N.N. Dadoenkova, M.I. Lyubchanskii, E.A. Shapovalov, Th. Rasing, Magnetic photonic crystals, Journal of Physics D: Applied Physics 36 (18) (2003) R277

[6] S.A. Nikitov, Ph. Tailhades, C.S. Tsai, Spin waves in periodic magnetic structures - magnonic crystals, Journal of Magnetism and Magnetic Materials 236 (3) (2001) 320-330

[7] H. Puszkarski, M. Krawczyk, Magnonic crystals-the magnetic counterpart of photonic crystals, Solid State Phenomena 94 (2003) 125-134.

[8] V.V. Kruglyak, S.O. Demokritov, D. Grundler, Magnonics, Journal of Physics D: Applied Physics 43 (2010) 264001.

[9] Yu. V. Gulyaev, S.A. Nikitov, L.V.Zhivotovskii, A.A. Klimov, Ph. Tailhades, L. Presmanes, C. Bonningue, C.S. Tsai, S.L. Vysotskii, Yu. A. Filimonov, Ferromagnetic films with magnon bandgap periodic structures: magnon crystals, JETP Letters 77 (10) (2003) 567-570.

10] S. Schnittger, S. Dreyer, Ch. Jooss, S. Sievers, U. Siegner, Magnetostatic interactions in patterned CoPt films embedded in a permalloy matrix, Applied Physics Letters 90 (2007) 042506

[11] S. Neusser, D. Grundler, Magnonics, Spin waves on the nanoscale, Advanced Materials 21 (2009) 2927-2932.

[12] A.O. Adeyeye, S. Jain, Coupled periodic magnetic nanostructures, Journal of Applied Physics 109 (2011) 07B903.

[13] M.E. Koleva, R.I. Tomov, P.A. Atanasov, Ch.G. Ghelev, O.I. Vankov, N.I. Mihailov, J. Lancok, M. Jelinek, Simultaneous laser-magnetic field treatment of $\mathrm{SrFe}_{12} \mathrm{O}_{19}$ thin films grown by pulsed laser deposition, Applied Surface Science 186(2002) $463-468$.

[14] D.E. Diaz-Droguett, R. El Far, V.M. Fuenzalida, A.L. Cabrera, In situ-Raman studies on thermally induced structural changes of porous $\mathrm{MoO}_{3}$ prepared in vapor phase under $\mathrm{He}$ and $\mathrm{H}_{2}$, Materials Chemistry and Physics 134 (2012) 631-638.

[15] D. Lee, H. Pan, S.H. Ko, H.K. Park, E. Kim, C.P. Grigoropoulos, Non-vacuum, single-step conductive transparent $\mathrm{ZnO}$ pattering by ultra-short pulsed laser annealing of solution-deposited nanoparticles, Applied Physics A 107 (1)(2012) $161-171$.

[16] S. Dhobale, N.M. Kulkarni, R.J. Choudhary, D.M. Phase, S.N. Kale, Engineering room temperature $\mathrm{SO}_{2}$ gas sensing via laser-annealed nanostructured $\mathrm{SnO}_{2}$ thin films, Science of Advanced Materials 4 (3-4) (2012) 475-479.

[17] M.H. Willemann, M.O. Thomson, Two stage laser processing of nanoparticle inks on flexible substrates for high performance electronics, Materials Research Society Symposium Proceedings 1340 (2011) 31-36.

[18] A.J. Pedraza, D.H. Lowndes, Surface engineering using eximer lasers, Proceedings of the SPIE - The International Society for Optical Engineering 3343 (1998) 829-839 
[19] O. Yavas, M. Takai, High-speed maskless laser patterning of thin films for giant microelectronics, Japanese Journal of Applied Physics 12B (Part 1 (38)) (1999) $7131-7134$.

[20] R. Nagai, T. Honma, T. Komatsu, Laser patterning of $\mathrm{ZnO}$ crystals on the surface of borosilicate glass, Journal of the American Ceramic Society 93 (3) (2010) 658-661.

[21] W.T. Hsiao, S.F. Tseng, C.H. Kuo, K.C. Huang, D. Chiang, P.C. Yao, M.F. Chen, Fabrication of electrodes on the aluminum doped zinc oxide thin films using an ultraviolet laser direct-patterning technology, Physics Procedia 19 (2011) $456-465$.

[22] V. Oliveira, N.I. Polushkin, O. Conde, R. Vilar, Laser surface patterning using a Michelson interferometer and femtosecond laser radiation, Optics and Laser Technology 44 (2012) 2072-2075.

[23] R. Sbiaa, S.N. Piramanayagam, Patterned media towards tano-bit magnetic recording: fabrication and challenges, Recent Patents on Nanotechnology 1 (2007) 29-40.

[24] S.N. Piramanayagam, J.P. Wang, Method of producing a magnetic recording medium, US Patent 6,699,332 B1 (2004).

[25] J. Pröll, R. Kohler, M. Torge, S. Ulrich, C. Ziebert, M. Bruns, H.J. Seifert, W. Pfleging, Laser microstructuring and annealing processes for lithium manganese oxide cathodes, Applied Surface Science 257 (23) (2011) 9968-9976.

[26] J. Pröll, R. Kohler, A. Mangang, S. Ulrich, M. Bruns, H.J. Seifert, W. Pfleging, Diode laser heat treatment of lithium manganese oxide films, Applied Surface Science 258 (12) (2012) 5146-5152.

[27] Ph. Tailhades, B. Gillot, A. Rousset, Mixed-valence defect ferrites: a new family of fine powders and thin films of spinel ferrites, Journal de Physique IV France 7 (C1) (1997) 249-252.
[28] W. Feitknecht, U. Mannweiler, Über die oxidation von $\mathrm{Fe}_{3} \mathrm{O}_{4} \mathrm{zu} \gamma$ - und $\alpha-\mathrm{Fe}_{2} \mathrm{O}_{3}$, Helvetica Chimica Acta 45 (1962) 2042-2057.

[29] K.J. Gallagher, W. Feitknecht, U. Mannweiler, Mechanism of oxidation of magnetite to $\gamma-\mathrm{Fe}_{2} \mathrm{O}_{3}$, Nature 217 (1968) 1118-1121.

[30] J.H. Nam, N.H. Jung, J.Y. Shin, J.H. Oh, The effect of cu substitution on the electrical and magnetic-properties of NiZn ferrites, IEEE Transactions on Magnetics 31 (6) (1995) 3985-3987.

[31] J. Mürbe, J. Töpfer, Ni-Cu-Zn ferrites for low temperature firing: I. Ferrite composition and its effect on sintering behavior and permeability, Journal of Electroceramics 15 (2005) 215-221.

[32] L. Bouet, Ph. Tailhades, I. Pasquet, C. Bonningue, S. Le Brun, A. Rousset, Cation-deficient spinel ferrites: application for high-density write-once optical recording, Japanese Journal of Applied Physics 38 (Part 1) (1999) 1826-1828.

[33] Ph. Tailhades, L. Presmanes, I. Pasquet, C. Bonningue, F. Laporte, Spinel oxides thin films for write-once optical recording with blue laser sources, Transactions of the Magnetics Society of Japan 2 (4) (2002) 198-201.

[34] Ph. Tailhades, C. Bonningue, I. Pasquet, L. Presmanes, Utilisation d'oxydes spinelles oxydables pour enregistrement optique, Patent PCT WO 03042991 (2003).

[35] M. Rosenberg, P. Nicolau, I. Bunget, On the electrical properties of some iron-copper and copper-manganese ferrites, Physica Status Solidi B 15 (1966) $521-530$.

[36] C. Gleitzer, J.B. Goodenough, Structure and Bonding, Springer Verlag, 1985, pp. 44-46.

[37] C. Villette, Ph. Tailhades, A. Rousset, Thermal behaviour and magnetic properties of acicular copper-cobalt ferrite particles, Journal of Solid State Chemistry 117 (1995) 64-72. 